\title{
The effects of the surface-exposed residues on the binding and hydrolytic activities of Vibrio carchariae chitinase A
} Supansa Pantoom ${ }^{1}$, Chomphunuch Songsiriritthigul ${ }^{2}$ and Wipa Suginta*1

Address: ${ }^{1}$ School of Biochemistry, Suranaree University of Technology, Nakhon Ratchasima 30000, Thailand and ${ }^{2}$ National Synchrotron Research Center, Nakhon Ratchasima 30000, Thailand

Email: Supansa Pantoom - aon_biochem@hotmail.com; Chomphunuch Songsiriritthigul - pook@nsrc.or.th; Wipa Suginta* - wipa@sut.ac.th

* Corresponding author

Published: 21 January 2008

BMC Biochemistry 2008, 9:2 doi:10.1 |86/147|-2091-9-2
Received: 17 September 2007

Accepted: 21 January 2008

This article is available from: http://www.biomedcentral.com/|47|-209|/9/2

(C) 2008 Pantoom et al; licensee BioMed Central Ltd.

This is an Open Access article distributed under the terms of the Creative Commons Attribution License (http://creativecommons.org/licenses/by/2.0), which permits unrestricted use, distribution, and reproduction in any medium, provided the original work is properly cited.

\begin{abstract}
Background: Vibrio carchariae chitinase A (EC3.2.I.I4) is a family-18 glycosyl hydrolase and comprises three distinct structural domains: i) the amino terminal chitin binding domain (ChBD); ii) the $(\alpha / \beta)_{8}$ TIM barrel catalytic domain $(\mathrm{CatD})$; and iii) the $\alpha+\beta$ insertion domain. The predicted tertiary structure of $V$. carchariae chitinase A has located the residues Ser33 \& Trp70 at the end of ChBD and Trp23I \& Tyr245 at the exterior of the catalytic cleft. These residues are surfaceexposed and presumably play an important role in chitin hydrolysis.

Results: Point mutations of the target residues of $V$. carchariae chitinase $A$ were generated by sitedirected mutagenesis. With respect to their binding activity towards crystalline $\alpha$-chitin and colloidal chitin, chitin binding assays demonstrated a considerable decrease for mutants W70A and Y245W, and a notable increase for S33W and W23 I A. When the specific hydrolyzing activity was determined, mutant W23IA displayed reduced hydrolytic activity, whilst Y245W showed enhanced activity. This suggested that an alteration in the hydrolytic activity was not correlated with a change in the ability of the enzyme to bind to chitin polymer. A mutation of Trp70 to Ala caused the most severe loss in both the binding and hydrolytic activities, which suggested that it is essential for crystalline chitin binding and hydrolysis. Mutations varied neither the specific hydrolyzing activity against $p \mathrm{NP}-[\mathrm{GlcNAc}]_{2}$, nor the catalytic efficiency against chitohexaose, implying that the mutated residues are not important in oligosaccharide hydrolysis.

Conclusion: Our data provide direct evidence that the binding as well as hydrolytic activities of $V$. carchariae chitinase $A$ to insoluble chitin are greatly influenced by $\operatorname{Trp} 70$ and less influenced by Ser33. Though Trp23I and Tyr245 are involved in chitin hydrolysis, they do not play a major role in the binding process of crystalline chitin and the guidance of the chitin chain into the substrate binding cleft of the enzyme.
\end{abstract}

\section{Background}

Chitin is a homopolysaccharide chain of $\mathrm{N}$-acetylglucosamine (GlcNAc or G1) units combined together with $\beta-1,4$ glycosidic linkages. Chitin is one of the most abundant biopolymers found in nature as constituent of fungal cell walls and exoskeletons of crustaceans and insects. However, the $\beta$-GlcNAc units that generally form intraand intermolecular $\mathrm{H}$-bonds make chitin completely insoluble in water and its use is thus limited. Several strategies have been developed for converting chitin into small 
soluble derivatives, which are more useful for applications in the fields of medicine, agriculture and industry. Enzymatic degradation of chitin using biocatalysts seems to be the method of choice since the type, quantity and quality of oligomeric products can be well controlled and the reaction occurs quickly and completely under mild conditions without generation of environmental pollutants.

Chitinases (EC3.2.1.14) are a diverse group of enzymes that catalyze the conversion of insoluble chitin to soluble oligosaccharides. They are found in a wide variety of organisms including virus, bacteria, fungi, insects, plants and animals [1-8]. In the carbohydrate active enzymes (CAZy) database http://www.cazy.org/, carbohydrate enzymes are first classified as glycosyl hydrolases (GH), glycosyl transferases (GT), polysaccharide lyases (PL), carbohydrate esterases (CE), and carbohydrate binding modules (CBM), and then further divided into numbered families with structurally-related catalytic and carbohydrate-binding modules. Following this classification, chitinases are commonly listed as family GH-18 and family GH-19 enzymes. Family-18 chitinases have the catalytic crevice located at top of the $(\alpha / \beta)_{8}$-TIM barrel domain $[9,10]$, whereas the catalytic domain of family-19 chitinases comprises two lobes, each of which is rich in $\alpha$-helical structure [11]. Bacteria such as Serratia marcescens, Bacillus circulans, Alteromonas sp. and marine Vibrios produce chitinases to synergistically degrade chitin and use it as a sole source of energy [1,12-16]. The mechanism of chitin degradation by bacterial chitinases was mainly derived from the outcome of structural studies or sitedirected mutagenesis [17-20]. Unlike chitooligosaccharides, chitin polymer has been presumed to unidirectionally enter the substrate binding cleft of chitinases under the guidance of a few surface-exposed residues at the exterior of the substrate binding cleft $[21,22]$. Those residues were identified as Trp33, Trp69, Phe232, and Trp245 in $S$. marcescens Chi A [18], Ser33, Trp70, Trp232, and Trp245 in Aeromonas caviae Chi1 [23], and Trp122 and Trp134 in B. circulans Chi A1 [17]. Structurally, the latter two residues are located in the equivalent locations of Tyr245 and Trp231, respectively of $V$. carchariae chitinase A (Fig. 1 and ref [17]). We previously isolated chitinase A from a marine bacterium, Vibrio carchariae [24]. The enzyme was found to be highly expressed upon induction with chitin and was active as a monomer of $63 \mathrm{kDa}$. The DNA fragment encoding the functional chitinase A was subsequently cloned into the PQE60 expression vector that was compatible to be highly expressed in E. coli type strain M15 [25]. Mutational studies confirmed that the conserved Glu315 acts as the catalytic residue in the substrateassisted mechanism $[26,27]$, whereas the aromatic residues including Trp168, Tyr171, Trp275, Trp397 and Trp570 participated in direct interactions with chitooligosaccharides [28]. In this study, site-directed mutagene- sis was employed in combination with following chitin binding assays and kinetic analysis to investigate the significance of the putative surface-exposed residues Ser33, Trp70, Trp231 and Tyr245 for the binding and hydrolytic activities of the Vibrio chitinase A.

\section{Results \\ Homology modeling and sequence analysis}

We previously reported gene isolation and sequence analysis of $V$. carchariae chitinase A precursor [25]. Sitedirected mutation of the active site residues showed that Glu315 plays an essential role in catalysis [26]. On the other hand, the conserved aromatic residues (Trp168, Tyr171, Trp275, Trp397 and Trp570) located within the substrate binding cleft of the enzyme were found to be important in binding to chitooligosaccharides [28]. Here, we have investigated the functional roles of four amino acid residues (Ser33, Trp70, Trp231 and Tyr245) at the surface of $V$. carchariae chitinase A. All of these residues have been proposed as functionally relevant to binding and hydrolysis of crystalline chitin $[17,18]$. Fig. 1 represents the modeled 3D-structure of $V$. carchariae chitinase A that was built based upon the crystal structure of $S$. marcescens chitinase A mutant E315L complexed with a chitohexamer [see Methods]. It can clearly be seen that the four residues linearly align with each other. Trp70 and Ser33 are positioned at the end of the $N$-terminal chitin binding domain (ChBD), whilst Trp231 and Tyr245 are found outside the substrate binding cleft where they are part of the TIM barrel catalytic domain.

When the amino acid sequences of several bacterial chitinases were compared, the $V$. carchariae chitinase A (Q9AMP1) exhibited highest sequence identity with chitinase A from $V$. harveyi HY01 (A6AUU6) (93\%), moderate identity with chitinase A from S. marcescens (P07254) and Enteromonas sp. (Q4PZF3) (47\%), and low identity with chitinase A1 from B. circulans (22\%). Surprisingly, extremely low sequence identity was observed when $V$. carchariae chitinase A was compared with chitinase A from V. splendidus (A3UMC6) (13\%) and V. cholerae (A6ACY6) $(11 \%)$.

A structure-based alignment of three chitinases, including $V$. carchariae chitinase A, S. marcescens chitinase A, and B. circulans WL-12 chitinase A1 was constructed and is displayed in Fig. 2A \&2B. Fig. 2A represents an alignment of the N-terminal ChBDs of the Vibrio and Serratia chitinases with the $C$-terminal fragment that covers the ChBD of the Bacillus chitinase $\mathrm{A} 1\left(\mathrm{ChBD}_{\text {chiA1 }}\right)$. The $\mathrm{ChBD}_{\text {chiAl }}$ consists of the residues 655 to 699 and deletion of this domain led to a severe loss in the binding activity to chitin as well as in the colloidal chitin-hydrolyzing activity, suggesting that this domain is essential for binding to insoluble chitin of this enzyme [29]. As shown in Fig. 2A, the residues 


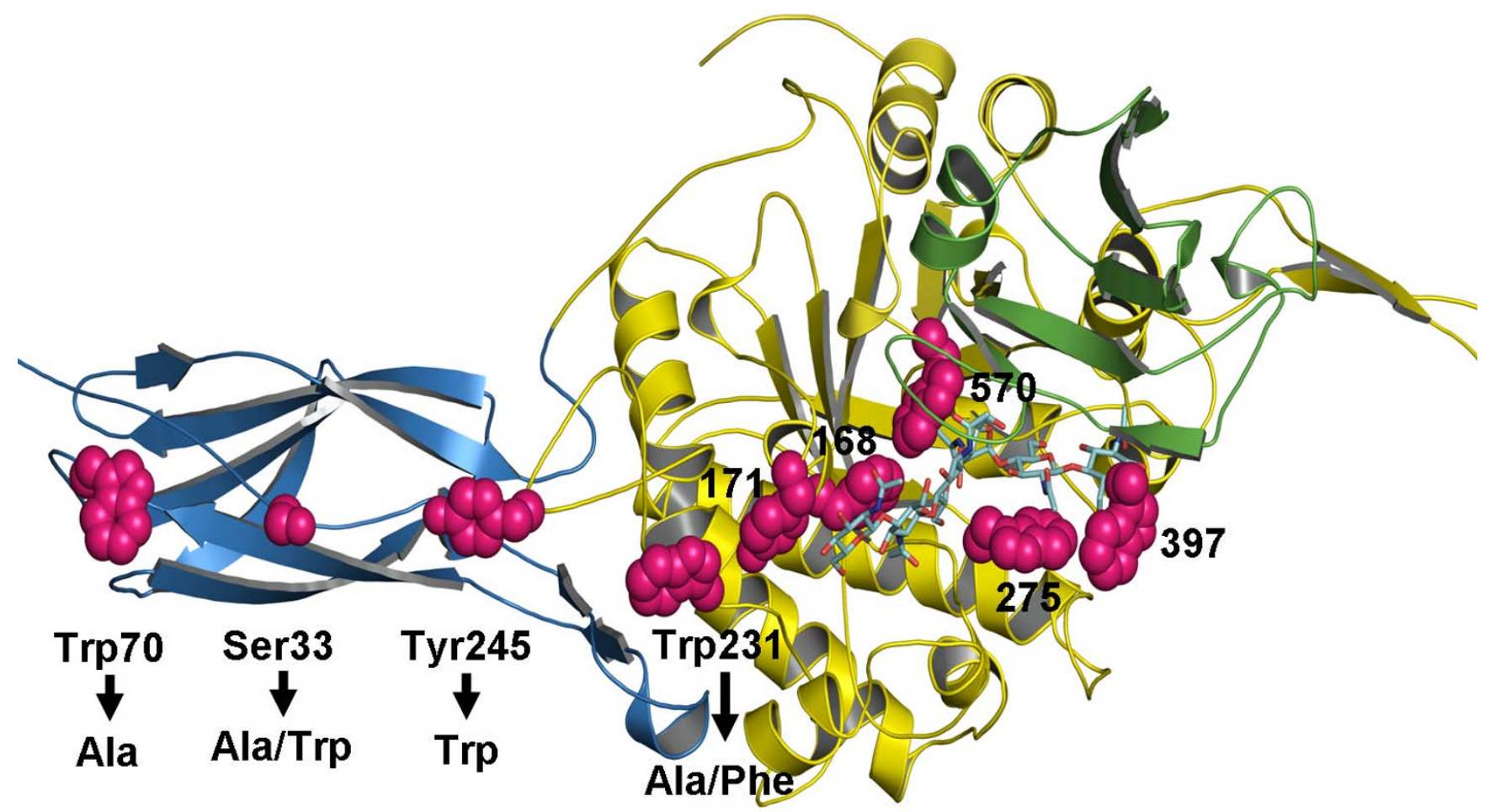

Figure I

The Swiss-Model 3D-structure of V. carchariae chitinase A. A ribbon representation of the 3D-structure of $V$. carchariae chitinase $A$ was constructed based on the $x$-ray structure of S. marcescens Chi A E3 I5L mutant as described in the text. The $\mathrm{N}$-terminal chitin binding domain is presented in cyan, the TIM barrel domain in yellow and the small insertion domain in green. The coordinates of [GlcNAc] 6 that are modeled in the active site of the Vibrio enzyme are shown as a stick model with $\mathrm{N}$ atoms in blue and $\mathrm{O}$ atoms in red. The mutated residues (Ser33, Trp70, Trp23I and Tyr245) and other substrate binding residues are also presented in stick model (magenta).

Trp656 and Trp687 of the $\mathrm{ChBD}_{\text {chiA1 }}$ are well aligned with Ser33 and Trp70 of $V$. carchariae chitinase A. However, the determination of the solution structure of the $\mathrm{ChBD}_{\text {chiA1 }}$ by Ikegami et al. [30] identified only Trp687 as a putative chitin binding residue, in addition to His681, Thr682, Pro689, and Pro693.

With respect to the alignment of the catalytic domain (Fig. 2B), Trp231 of the Vibrio chitinase is equivalent to Trp122 and to Phe 232 of the Bacillus and Serratia chitinases. For Tyr245, this residue is replaced by Trp134 and Trp245 in the $B$. circulans and $S$. marcescens sequences, respectively. The sequence alignment additionally demonstrates the residues Ser33 and Trp70 within the flexible loops that join two strands in the chitin binding region. The residues Trp245 and Tyr231 are found as part of the catalytic ( $\alpha$ / $\beta)_{8}$ TIM barrel, where Tyr245 is exposed on the loop that joins helices 2(3) and 2(4) together and $\operatorname{Trp} 231$ is the only residue being found in an $\alpha$-helix (helix 2(3)).

\section{Expression and purification of chitinase $A$ and mutants}

To investigate the binding and hydrolytic activities of $V$. carchariae chitinase $\mathrm{A}$, target residues as named above were mutated by sited-directed mutagenesis. According to the employed system, the recombinant chitinases were expressed as the $C$-terminally (His) ${ }_{6}$ tagged fusion protein (see Methods). After single-step purification using NiNTA agarose affinity chromatography, the yields of the purified proteins was estimated to be approx. 20 to 25 $\mathrm{mg} / \mathrm{ml}$ per litre of bacterial culture. As analyzed by SDSPAGE, all the mutated proteins displayed a single band of molecular weight of $63 \mathrm{kDa}$ (data not shown), which is identical to the molecular weight of the wild-type enzyme. 

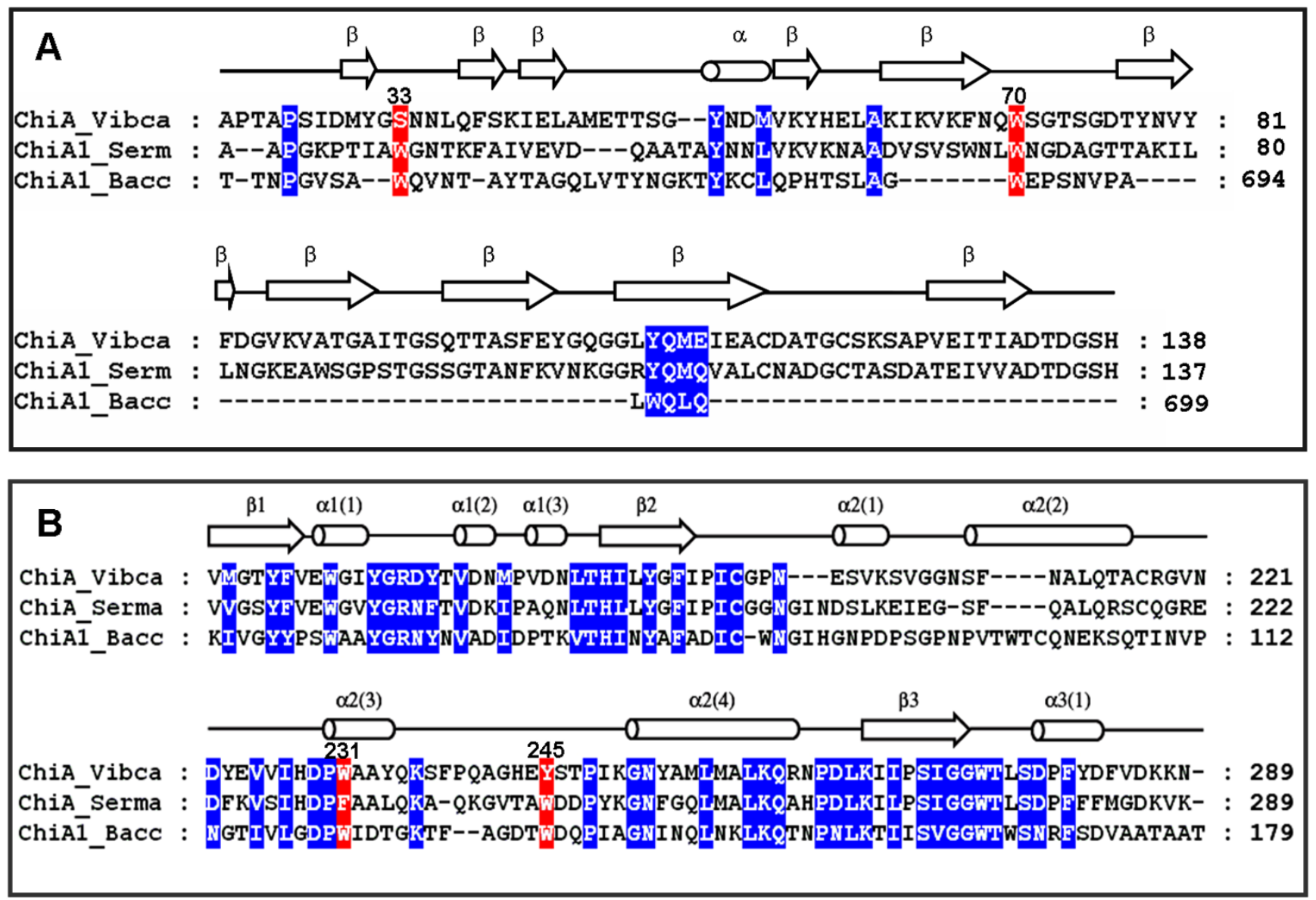

Figure 2

A structure-based alignment of $V$. carchairae chitinase $A$ with $S$. marcescens chitinase $A$ and $B$. circulans chitinase AI. A) The N-terminal ChBDs of $V$. carchariae chitinase A (residues 22-138) and S. marcescens chitinase A (residues 24I37) were aligned with the $C$-terminal fragment (residues 648-699), covering the ChBD of $B$. circulans WL- 2 chitinase AI. B) An alignment of the catalytic domain of the three bacterial chitinases with residues 160 to 289 of $V$. carchariae chitinase $A$ being displayed. The chitinase sequences were retrieved from the Swiss-Prot/TreEMBL protein databases, aligned using "MegAlign" in the DNASTAR package, and displayed in Genedoc. The secondary structure of $V$. carchariae chitinase A was predicted from the PHD method in PredictProtein using S. marcescens as template [see texts]. Conserved residues are shaded in blue, whereas the residues that are aligned with Ser33, Trp70, Trp23I, and Tyr245 of V. carchariae chitinase A are shaded in red. ChiA_Vibca: V. carchariae chitinase A (Q9AMPI), ChiA_Serma: S. marcescens chitinase A (P07254), and ChiAI_Bacc: B. circulans chitinase AI (P20533). $\beta$-strand is represented by an arrow, $\alpha$-helix by a cylinder and loop by a straight line.

\section{Effects of mutations on the chitin binding activities of chitinase A}

To minimize hydrolysis, all the binding experiments were carried out on ice. Bindings of the wild-type chitinase and mutants to colloidal chitin were initially investigated as a function of time. After a removal of the enzyme bound to chitin, decreases in concentration of the unbound enzyme remaining in the supernatant was monitored discretely at different time points of 0 to $120 \mathrm{~min}$. Fig. 3 demonstrates that the binding process took place rapidly and reached equilibrium within $5 \mathrm{~min}$. The relative binding activity of each mutant to colloidal chitin is following the order $\mathrm{W} 231 \mathrm{~A}>\mathrm{S} 33 \mathrm{~W}>\mathrm{WT} \cong \mathrm{W} 231 \mathrm{~F}>\mathrm{S} 33 \mathrm{~A}>\mathrm{Y} 245 \mathrm{~W}>\mathrm{W} 70 \mathrm{~A}$.
The binding activity of the individual mutants relative to the one of the wild-type enzyme was further examined with colloidal chitin and $\alpha$-chitin polysaccharides at a single time point of 60 minutes. In general, the wild-type and mutant chitinases expressed greater binding activity towards colloidal chitin. A comparison of the level of binding of the engineered enzymes to the two substrates revealed a similar pattern (Fig. 4). For both polysaccharides, W70A and Y245W displayed lower binding activity than the wild-type enzyme. S33A and W231F showed a modest increase in binding to crystalline $\alpha$-chitin and decreased level of binding to colloidal chitin. Mutants S33W and W231A, on the other hand, displayed higher 


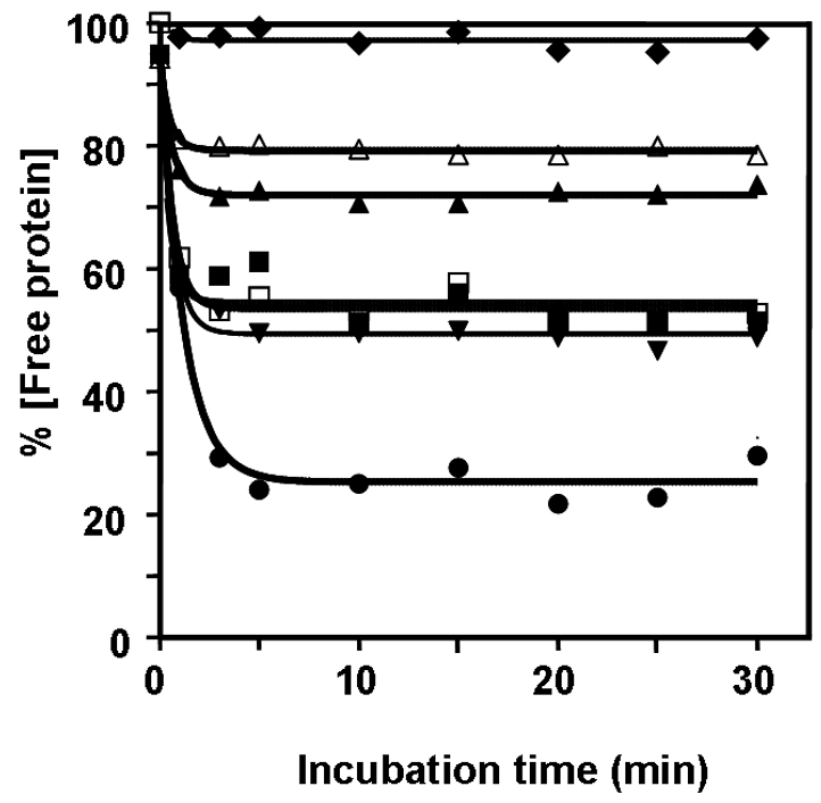

Figure 3

Time-course of binding of chitinase $A$ and mutant enzymes to colloidal chitin. Chitinases ( $1 \mu \mathrm{mol}$ in 100 $\mathrm{mM}$ sodium acetate buffer, $\mathrm{pH} 5.5$ ) were incubated with $\mathrm{I} .0$ $\mathrm{mg}$ colloidal chitin at $0^{\circ} \mathrm{C}$. Decreases in free enzyme concentration were determined at different time points from 0-30 min by Bradford's method. Each data value was calculated from triplicate experiments. Symbols: wild-type (black square); S33A (black upward-pointing triangle); S33W (black downward-pointing triangle); W70A (black diamond); W23 IA (black circle); W23 IF (open square); and Y245W (open triangle).

effectiveness in the binding to both substrates. Of all, mutant W231A displayed highest binding activity and W70A exhibited lowest activity. Especially, no detectable binding to crystalline $\alpha$-chitin was observed with mutant W70A.

Adsorption isotherms of chitinase mutants to colloidal chitin were carried out relative to that of the wild-type enzyme. Fig. 5 represents a non linear plot of the adsorption isotherms obtained at a fixed concentration of colloidal chitin but varied concentrations of the enzyme (See Methods). In comparison to the wild-type enzyme, mutants S33W and W231A exhibited significantly higher binding activity, whereas mutants W70A, S33A, W231F and $\mathrm{Y} 245 \mathrm{~W}$ had a notably decreased binding activity. When the dissociation binding constants $\left(K_{\mathrm{d}}\right)$ were estimated from the non-linear regression function, it was found that the $K_{\mathrm{d}}$ value of wild-type $(0.95 \pm 0.11 \mu \mathrm{M})$ was slightly larger than the $K_{\mathrm{d}}$ values of S33W $(0.84 \pm 0.09$ $\mu \mathrm{M})$ and $\mathrm{W} 231 \mathrm{~F}(0.88 \pm 0.09 \mu \mathrm{M})$, but remarkably greater than the value of $\mathrm{W} 231 \mathrm{~A}(0.26 \pm 0.03 \mu \mathrm{M})$. In contrast, significantly higher $K_{\mathrm{d}}$ values than the wild-type value were observed with S33A $(1.50 \pm 0.11 \mu \mathrm{M})$, W70A $(2.30$ $\pm 0.25 \mu \mathrm{M})$, and $\mathrm{Y} 245 \mathrm{~W}(1.60 \pm 0.16 \mu \mathrm{M})$. These estimated $K_{\mathrm{d}}$ values gave a notation of the enzyme's binding strength in the following order W231A $>$ S33W $>$ W231F $>$ wild-type $>$ S33A $>$ Y245W $>$ W70A, which is in absolute accordance with the binding activities determined by the chitin binding assay (see Fig. 4) and the kinetic data as described below.

\section{Effects of mutations on the hydrolytic activities of chitinase $A$}

The effects of mutations on the hydrolytic activity of $V$. carchariae chitinase A were further studied by exposing the wild-type and modified enzymes to pNP-[GlcNAc] ${ }_{2}$, colloidal chitin and crystalline $\alpha$-chitin. The specific hydrolyzing activity for the three different substrates was subsequently determined. From all the mutants, only W231A displayed a slightly reduced specific hydrolyzing activity against the $p$ NP substrate (Table 1 ).

Unlike the pNP-glycoside, strong effects on the hydrolytic activities were observed with the insoluble polymeric substrates. The hydrolyzing activity against crystalline $\alpha$-chitin was completely abolished in case of mutants S33A, W70A and W231A/F but improved for mutants S33W and Y245W at levels of $166 \%$ and $250 \%$ of the wild-type activity, respectively. A similar trend was also seen with colloi-

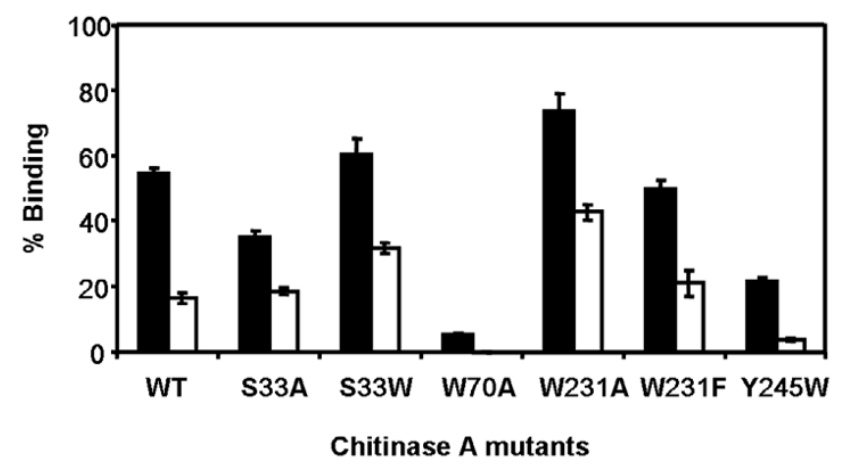

Figure 4

Binding of chitinase $A$ and mutants to insoluble chitin. The binding assay set as described in the text was incubated with crystalline $\alpha$-chitin or colloidal chitin for $60 \mathrm{~min}$. The \% binding $=\left[\frac{E_{t}-E_{f}}{E_{t}}\right] \times 100 ;$ where $E_{t}$ is initial enzyme concentration and $E_{f}$ is the free enzyme concentration after binding. Closed and open bars represent \% binding to colloidal chitin and crystalline $\alpha$-chitin, respectively. The presented data are mean values obtained from three independent sets of the experiment. 


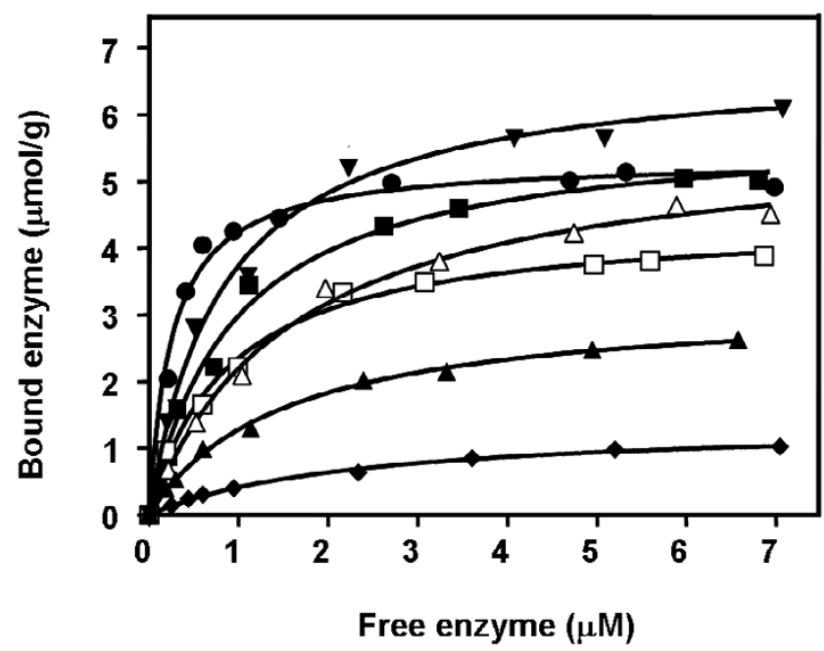

Figure 5

Equilibrium adsorption isotherms of wild-type and mutant chitinases $\mathbf{A}$ to colloidal chitin. The reaction assay $(500 \mu \mathrm{l})$ contained $\mathrm{I} .0 \mathrm{mg}$ chitin and varied concentrations of enzyme from 0 to $7.0 \mu \mathrm{M}$. After $60 \mathrm{~min}$ of incubation at $0^{\circ} \mathrm{C}$, the reaction mixture was centrifuged and concentrations of $E_{b}$ and $E_{f}$ were determined as described in the text. Symbols: wild-type (black square); S33A (black upward-pointing triangle); S33W (black downward-pointing triangle); W70A (black diamond); W23 I A (black circle); W23 IF (open square); and Y245W (open triangle).

dal chitin. However, for this substrate S33A, W70A and W231A/F not completely abolished but markedly decreased hydrolyzing activity, while S33W (119\%) and Y245W (152\%) again where the ones that displayed higher activity than wild-type enzyme. The most severe loss of the specific hydrolyzing activity towards colloidal chitin was detected for mutant W70A, which had a substitution of Trp70 to Ala.

\section{Steady-state kinetics of chitinase $A$ and mutants}

The kinetic parameters of the hydrolytic activity of chitinase A and mutants were finally determined with chitohexaose and colloidal chitin as substrates. As presented in Table 2, mutations of the chosen residues led for the response of enzyme values towards the hexachitooligomer to concomitant decreases in both the $K_{\mathrm{m}}$ and $k_{\text {cat }}$ values. For all the mutants, however, the overall catalytic efficiency $\left(k_{\text {cat }} / K_{\mathrm{m}}\right)$ was not much different to the value observed for the wild-type enzyme. In contrast, the kinetic properties of the enzyme against colloidal chitin were significantly modified by the mutations. The $K_{\mathrm{m}}$ values of S33A (2.07 $\left.10^{1} \mathrm{mg} \mathrm{ml}^{-1}\right)$, W70A (2.26 $\left.10^{1} \mathrm{mg} \mathrm{ml}^{-1}\right)$, and Y245W (1.82 $\left.10^{1} \mathrm{mg} \mathrm{ml}^{-1}\right)$ were higher than the wild-type $K_{\mathrm{m}}\left(1.7410^{1} \mathrm{mg} \mathrm{ml}^{-1}\right)$ whereas S33W $\left(1.5810^{1} \mathrm{mg} \mathrm{ml}^{-1}\right)$ and W231A (1.01 $10^{1} \mathrm{mg} \mathrm{ml}^{-1}$ ) had considerably lower $K_{\mathrm{m}}$ compared to the reference value. Mutations that caused a large decrease in the enzyme's catalytic activity, $k_{\text {cat }}$, were Ser33 to Ala, Trp70 to Ala and Trp231 to Ala/ Phe, whereas mutations of Ser33 to Trp and Tyr245 to Trp elevated $k_{\text {cat }}$ values instead. The overall catalytic efficiency $\left(k_{\text {cat }} / K_{\mathrm{m}}\right)$ that was calculated for the hydrolysis of colloidal chitin was to more or less extent either reduced (for S33A, W70A, W231A and W231F) or increased (for S33W and Y245W).

\section{Discussion}

This study describes the possible role of Ser33, Trp70, Trp231, and Tyr245 in chitin binding and hydrolysis. Point mutations of these residues were introduced by sitedirected mutagenesis and changes in the binding and hydrolytic activities of the enzyme as a result of the amino acid substitution were subsequently investigated for various substrates. Chitin binding assays (Fig. 3 \&4) demonstrate a decrease in the binding activity of mutants S33A, W70A and Y245W to various extents. However, the most severe effect was observed with W70A. A time course study displayed no binding activity of W70A but retained activ-

Table I: Specific hydrolyzing activity of chitinase $A$ and mutants. The reducing sugar assay was carried out against crystalline and colloidal chitin. The release of the hydrolytic products was calculated from a standard curve of [GIcNAc] ${ }_{2}$. On the other hand, the specific hydrolyzing activity against $p N P-[G I c N A c]_{2}$ was determined by the colorimetric assay. The release of $p N P$ was estimated from a standard curve of pNP

\begin{tabular}{|c|c|c|c|}
\hline \multirow[t]{2}{*}{ Protein } & \multicolumn{3}{|c|}{ Specific hydrolyzing activity (U/ $\mu \mathrm{mol}$ protein $)^{a}$} \\
\hline & Crystalline chitin & Colloidal chitin & pNP-[GlcNAc $]_{2}$ \\
\hline Wild-type & $0.59 \pm 0.02(100)^{\mathrm{b}}$ & $12.9 \pm 0.22(100)$ & $50.5 \pm 1.13(100)$ \\
\hline S33A & n.d.c & $8.5 \pm 0.50(66)$ & $58.0 \pm 1.08(115)$ \\
\hline S33W & $1.00 \pm 0.08(166)$ & $15.3 \pm 0.32(119)$ & $54.0 \pm 2.55(107)$ \\
\hline W70A & n.d. & $4.3 \pm 0.17(33)$ & $52.8 \pm 2.14(105)$ \\
\hline W23IA & n.d. & $6.6 \pm 0.26(5 I)$ & $45.2 \pm 2.00(90)$ \\
\hline W23IF & n.d. & $9.2 \pm 0.49(7 \mathrm{I})$ & $54.3 \pm 2.85(108)$ \\
\hline Y245W & $1.49 \pm 0.09(250)$ & $19.6 \pm 0.53(152)$ & $53.6 \pm 1.61(106)$ \\
\hline
\end{tabular}

\footnotetext{
a One unit of chitinase is defined as the amount of enzyme that releases I $\mu$ mol of $[\mathrm{GlcNAc}]_{2}$ or I nmol of $p N P$ per min at $37^{\circ} \mathrm{C}$.

b Values in parentheses represent relative specific hydrolyzing activities (\%).

c Non-detectable activity.
} 
Table 2: Kinetic parameters of substrate hydrolysis by chitinase A wild-type and mutants. A kinetic study was carried out using 0-5\% $(w / v)$ colloidal chitin and $0-500 \mu \mathrm{M}$ chitohexaose as substrates. After 10 minutes of incubation at $37^{\circ} \mathrm{C}$, the amounts of the reaction products were determined from a standard curve of [GIcNAc $]_{2}$

\begin{tabular}{|c|c|c|c|c|c|c|}
\hline \multirow{2}{*}{$\begin{array}{c}\text { Chitinase } \mathbf{A} \\
\text { variant }\end{array}$} & \multicolumn{3}{|c|}{ Chitohexaose } & \multicolumn{3}{|c|}{ Colloidal chitin } \\
\hline & $K_{m}(\mu M)$ & $k_{\text {cat }}\left(\mathbf{s}^{-1}\right)$ & $k_{\mathrm{cat}} / K_{\mathrm{m}}\left(\mathrm{s}^{-1} \mathrm{M}^{-1}\right)$ & $K_{\mathrm{m}}\left(10^{1} \mathrm{mg} \mathrm{ml}^{-1}\right)$ & $k_{\text {cat }}\left(s^{-1}\right)$ & $\begin{array}{c}k_{c a t} / K_{m}\left(10^{-1} \mathrm{~s}^{-1 /} /\right. \\
\left.\mathrm{mg} \mathrm{m}^{-1}\right)\end{array}$ \\
\hline Wild-type & $218 \pm 22.0$ & 2.9 & $1.3 \times 10^{3}(100)^{\mathrm{a}}$ & $1.74 \pm 0.1$ & 1.2 & $0.7(100)$ \\
\hline S33A & $|7| \pm 20.5$ & 2.6 & $1.5 \times 10^{3}(115)$ & $2.07 \pm 0.2$ & 0.9 & $0.4(57)$ \\
\hline S33W & $210 \pm 15.4$ & 2.8 & $1.3 \times 10^{3}(100)$ & $1.58 \pm 0.2$ & 1.4 & 0.9 (I29) \\
\hline W70A & $185 \pm 22.0$ & 2.5 & $1.3 \times 10^{3}(100)$ & $2.26 \pm 0.4$ & 0.4 & $0.2(29)$ \\
\hline W23IA & $189 \pm 13.2$ & 2.6 & $1.4 \times 10^{3}(108)$ & $1.01 \pm 0.2$ & 0.6 & $0.6(86)$ \\
\hline W23IF & $163 \pm 10.3$ & 2.4 & $1.5 \times 10^{3}(115)$ & $1.70 \pm 0.2$ & 0.9 & $0.5(7 \mathrm{I})$ \\
\hline Y245W & $201 \pm 13.1$ & 2.6 & $1.3 \times 10^{3}(100)$ & $1.82 \pm 0.2$ & 1.7 & 0.9 (129) \\
\hline
\end{tabular}

a Relative catalytic efficiencies (\%) are shown in parentheses.

ity of other mutants to colloidal chitin (Fig. 3). This strongly suggested that Trp70 is the major determinant for insoluble chitin binding. Sugiyama and colleagues previously employed the reducing-end labeling technique and the tilt micro-diffraction method $[21,22]$ to illustrate the molecular directionality of crystalline $\beta$-chitin hydrolysis by $S$. marescens chitinase A and B. chitinase chitinase A1. If the chitin polymer enters the substrate binding cleft of $V$. carchariae chitinase A from the reducing end as described for the Serratia and Bacillus enzymes, Trp70 will likely serve as a platform for the arrival of a chitin molecule. This idea is well complimented by the location of the residue at the end of ChBD. A remarkable loss of the specific hydrolyzing activity as well as the decrease in the rate of enzyme turnover $\left(k_{\text {cat }}\right)$ that was observed for mutant W70A is hence explainable by the loss of the binding strength due to a substitution of Trp to Ala and an associated change in the hydrophobic interactions. A similar performance was seen for residue Ser33. Although to a lesser extent, a mutation of Ser33 to Ala also led to decreased binding activity, while its mutation to Trp improved binding activity. This finding provides additional evidence that binding of the chitin chain to the ChBD is cooperatively taken place via hydrophobic interactions and influenced by the molecular setting in this region.

The most striking observations were made with the residue Trp231. As demonstrated by the modeled 3D-structure (see Fig. 1), the residue Trp231 is placed at the outermost of the catalytic surface, thereby lying closest to the non-reducing end of the substrate binding cleft. The observed drastic improvement (rather than reduction) in the binding efficiency of mutant W231A could only be explained as a removal of the side-chain blockage. Hence, the reduced hydrolyzing activity of mutant W231A was unlikely influenced by changes in the binding acitivity as a result of the alanine substitution of Trp231. Apparently, the same phenomenon was previously recognized in $S$. marcescens chitinase A [18], with which a mutation of Phe232 to Ala seriously diminished the hydroyzing acitivty but left the binding activities to both colloidal chitin and $\beta$-chitin microfibrils unchanged.

When the next residue in line (Tyr245) (see Fig. 1) was mutated to a bulkier side-chain (Trp), inverse effects (reduced binding but improved hydrolysis) were observed. This complimented the idea of the binding barrier around the entrance hall of the catalytic domain by Trp231 and Tyr245. Similar findings were also recognized with a cellulose degrading enzyme, Thermobifida fusca endoglucanase (Cel9A) [31]. With this enzyme, it was observed that mutations of the surface-exposed cellulose binding residues Arg557 and Glu559 to Ala (mutant R557A/E559A) led to a severe loss in the hydrolytic activity against crystalline cellulose, but a change in the binding activity was not at all observed. Structurally, the residues Arg557 and Glu559 are found on the surface of the cellulose binding module (CBM), closest to the catalytic binding cleft of Cel9A. Therefore, the effects of Arg557 and Glu559 would be explained in analogy to those of Trp231 and Tyr245 in V. carchariae chitinase A.

In marked contrast, observations made with the Vibrio Trp231 mutation were different to the studies of Li et al. on A. caviae Chi 1 [23] and of Watanabe et al. on B. circulans Chi A1 [17]. Mutations of Trp232 and Trp245 (in A. caviae Chi 1 ) or Trp122 and Trp 134 (in B. circulans) to alanine resulted in a marked loss in both binding and hydrolyzing acitivities, especially againts crystalline $\beta$-chitin. Therefore, the reduced hydrolytic activities were assumed to be associated with the weaker binding of the two corresponding residues. Based on their mutational data, the residues seemed to participate directly in binding 
to crystalline chitin, and subsequently cooperatively assisting the chitin chain to penetrate through the catalytic cleft of A. caviae or B. circulans chitinase.

Indeed, the above-mentioned event that took place in the A. carviae and B. circulans chitinases did not seem to be the case for the $V$. carchariae chitinase A due to different behaviors of Trp231 and Tyr245 found for the Vibrio enzyme. Our data suggested that a possible action of $V$. carchariae chitinase A on insoluble chitin could proceed as follows: i) Initial binding of a chitin chain to the ChBD. This process is most influenced by the hydrophobic interaction set between the incoming sugar and residue Trp70, which is located at the doorway of the ChBD; ii) Further binding of GlcNAc units. However, binding through Ser33 remains inconclusive, since the mutational results revealed that Ser33 did not act as a powerful binding residue. Alternatively, this binding step might be made through a different surface-exposed aromatic residue located nearby; and iii) Sliding of bound sugar units of the chitin chain into the substrate binding cleft. Based on the 'slide and bend' mechanism proposed by Watanabe and others $[17,21,32]$, the sliding process is achieved by cooperative interactions with other surface-exposed aromatic residues located close to the entrance of the substrate binding cleft. However, our data strongly suggested that the chitin chain movement most likely takes place via an interaction with different surface-exposed aromatic residues other than Tyr245 and Trp231.

When $p$ NP-[GlcNAc $]_{2}$ was used as a substrate, hydrolyzing activities of the mutated enzymes and the wild-type enzyme were almost indistinguishable. This observation and the essentially unchanged catalytic efficiency $\left(\mathrm{k}_{\mathrm{cat}} /\right.$ $K_{\mathrm{m}}$ ) of all mutants compared to wild-type enzyme clearly pointed out that Ser33, Trp70, Trp231 and Tyr245 do not play a major role in the process of hydrolysis of soluble chitooligosaccharides.

\section{Conclusion}

Point mutations of four surface-exposed residues of $V$. carchariae chitinase A and subsequent experiments on chitin binding and hydrolysis were performed. Trp70, which is located at the $N$-terminal end of the chitin binding domain, was identified as the most crucial residue in colloidal and crystalline chitin binding and consequently their hydrolysis. The residues Trp231 and Tyr245, both located nearer to the substrate-binding cleft, influenced chitin hydrolysis but not really insoluble chitin binding.

\section{Methods}

Bacterial strains and expression plasmid

Escherichia coli type strain DH5 $\alpha$ was used for routine cloning, subcloning and plasmid preparation. Supercompetent E. coli XL1Blue (Stratagene, La Jolla, CA, USA) was the host strain for the production of mutagenized DNA.E. coli type strain M15 (Qiagen, Valencia, CA, USA) and the pQE 60 expression vector harboring chitinase A gene fragments were used for a high-level expression of recombinant chitinases.

\section{A structural based sequence alignment and homology modeling}

The amino acid sequence alignment was constructed by the program MegAlign using CLUSTAL method algorithm in the DNASTAR package (Biocompare, Inc., CA, USA) and displayed in Genedoc [33]. The amino acid sequence of the $V$. carchariae chitinase was aligned with five selected bacterial chitinase sequences available in the Swiss-Prot or TrEMBL database (see Results). The secondary structure elements of $V$. carchariae chitinase A were obtained by the PHD method available in PredicProtein [34]. The modeled tertiary structure of the Vibrio chitnase was built by Swiss-Model and displayed by Swiss-Pdb Viewer [35] using the x-ray structure of $S$. marcescens chitinase A E315L mutant complex with hexaNAG (PDB code: $1 \mathrm{NH} 6$ ) as structure template. The co-ordinates of $[\mathrm{GlcNAc}]_{6}$ were modeled into the active site of the Vibrio enzyme and the target residues were located by superimposing the $\mathrm{C}_{\alpha}$ atoms of 459 residues of $V$. carchariae chitinase A with the equivalent residues of $S$. marcescens E315L complex, using the program Superpose available in the CCP4 suit [36]. The predicted structure was viewed with Pymol [37].

\section{Mutation design and site-directed mutagenesis}

Site-directed mutagenesis was carried out by PCR using QuickChange site-directed mutagenesis kit (Stratagene). The pQE60 plasmid harbouring chitinase A DNA lacking the residues 598-850 C-terminal fragment was used as DNA template [25]. The primers (Bio Service Unit, Thailand) used for the mutagenesis are summarized in Table 3 . The success of newly-generated mutations was confirmed by automated DNA sequencing (BSU, Thailand). The programs used for nucleotide sequence analyses were obtained from the DNASTAR package (DNASTAR, Inc., Madison, USA).

\section{Expression and purification of recombinant wild-type and mutant chitinases}

The pQE60 expression vector harboring the DNA fragment that encodes wild-type chitinase A were highly expressed in E. coli M15 cells and the recombinant proteins purified as described elsewhere [28]. Briefly, the cells were grown at $37^{\circ} \mathrm{C}$ in Luria Bertani (LB) medium containing $100 \mu \mathrm{g} / \mathrm{ml}$ ampicillin until $\mathrm{OD}_{600}$ reached 0.6, and then $0.5 \mathrm{mM}$ of isopropyl thio- $\beta$-D-galactoside (IPTG) was added to the cell culture for chitinase production. After $18 \mathrm{~h}$ of induction at $25^{\circ} \mathrm{C}$, the cell pellet was collected by centrifugation, re-suspended in $15 \mathrm{ml}$ of lysis buffer (20 mM Tris-HCl buffer, pH 8.0, containing 150 
Table 3: Primers used for mutagenesis

\begin{tabular}{ll}
\hline Point mutation & Oligonucleotide sequence \\
\hline Ser33 $\rightarrow$ Ala & Forward 5'-CGATATGTACGGTGCGaAATAACCTTCAATTTTC-3' \\
Ser33 $\rightarrow$ Trp & Reverse 5'-GAAAATTGAAGGTTATTCGCACCGTACATATCG-3' \\
& Forward 5'-CGATATGTACGGTTGGAATAACCTG'CAATTTC-3' \\
Trp70 $\rightarrow$ Ala & Reverse 5'-GAAAATTGCAGGTTATTCCAACCGTACATATCG-3' \\
& Forward 5'-GAAATTTAACCAGGCGAGTGGCACATCTG-3' \\
Trp23I $\rightarrow$ Ala & Reverse 5'-CAGATGTGCCACTCGCCTGGTTAAATTTC-3' \\
& Forward 5'-GTTATCCATGATCCGGCGgcagcttatc-3' \\
Trp23I $\rightarrow$ Phe & Reverse 5'-GATAAGCTGCCGCCGGATCATGGATAAC-3' \\
& Forward 5'-GGTTATCCATGACCCGTTTGCAGCTTATCAG-3' \\
Tyr245 $\rightarrow$ Trp & Reverse 5'-CTGATAAGCTGCAAACGGGTCATGGATAACC-3' \\
& Forward 5'-CAGGTCATGAATGGAGCACGCCAATCAAG-3' \\
& Reverse 5'-CTTGATTGGCGTGCTCCATTCATGACCTG-3'
\end{tabular}

a Sequences underlined indicate the mutated codons.

b Sequences in bold represent the codon being modified to achieve the $T_{m}$ value as required for QuickChange site-directed mutagenesis.

$\mathrm{mM} \mathrm{NaCl}, 1 \mathrm{mM}$ phenylmethylsulphonyl fluoride (PMSF), and $1.0 \mathrm{mg} / \mathrm{ml}$ lysozyme), and then lysed on ice using an Ultrasonic homogenizer. The supernatant obtained after centrifugation at $12,000 \mathrm{~g}$ for $1 \mathrm{~h}$ was instantly subjected to Ni-NTA agarose affinity chromatography following the Qiagen's protocol. After SDS-PAGE analysis [38], the chitinase containing fractions were pooled and then applied to Vivaspin-20 membrane filtration (Mr 10000 cut-off, Vivascience AG, Hannover, Germany) to concentrate the protein and to remove imidazole. A final concentration of the protein was determined by Bradford's method [39] using a standard calibration curve constructed from BSA (0-25 $\mu \mathrm{g})$.

\section{Chitinase activity assays}

The colorimetric assay was carried out in a 96-well microtiter plate using $p$ NP-[GlcNAc $]_{2}$ (Bioactive Co., Ltd., Bangkok, Thailand) as substrate. A 100- $\mu$ l assay mixture, comprising protein sample $(10 \mu \mathrm{l}), 500 \mu \mathrm{M}$ pNP-(Glc$\mathrm{NAc}_{2}$, and $100 \mathrm{mM}$ sodium acetate buffer, $\mathrm{pH}$ 5.5, was incubated at $37^{\circ} \mathrm{C}$ for $10 \mathrm{~min}$ with shaking. After the reaction was terminated by the addition of $1.0 \mathrm{M} \mathrm{Na}_{2} \mathrm{CO}_{3}(50$ $\mu \mathrm{l})$, the amount of $p$-nitrophenol ( $p \mathrm{NP}$ ) released was determined by $\mathrm{A}_{405}$ in a microtiter plate reader (Applied Biosystems, Foster City, CA, USA). Molar concentrations of the $p \mathrm{NP}$ product were estimated from a calibration curve of $p N P(0-30 \mathrm{nmol})$. Alternatively, chitinase activity was measured by a reducing-sugar assay. The reaction mixture $(500 \mu \mathrm{l})$, containing $1 \%(\mathrm{w} / \mathrm{v})$ colloidal chitin (prepared based on Hsu \& Lockwood [40]), $100 \mathrm{mM}$ sodium acetate buffer, $\mathrm{pH} 5.5$, and $100 \mu \mathrm{g}$ chitinase $\mathrm{A}$, was incubated at $37^{\circ} \mathrm{C}$ in a Thermomixer comfort (Eppendorf AG, Hamburg, Germany). After 15 min of incubation, the reaction was terminated by boiling at $100^{\circ} \mathrm{C}$ for $5 \mathrm{~min}$, and then centrifuged at $5,000 \mathrm{~g}$ for 10 min to precipitate the remaining chitin. A $200-\mu l$ superna- tant was then subjected to DMAB assay following Bruce et al. [41]. The release of the reducing sugars as detected by $\mathrm{A}_{585}$ was converted to molar quantity using a standard calibration curve of $[\mathrm{GlcNAc}]_{2}(0-1.75 \mu \mathrm{mol})$. For crystalline $\alpha$-chitin, chitinase activity assay was carried out as described for colloidal chitin with $400 \mu \mathrm{g}$ of chitinase A included in the assayed mixture.

\section{Chitin binding assays}

Chitin binding assays were carried out at $0^{\circ} \mathrm{C}$ to minimize hydrolysis. For time course studies, a reaction mixture $(500 \mu \mathrm{l})$, containing $1.0 \mu \mathrm{mol}$ enzyme, and $1.0 \mathrm{mg}$ of chitin in $20 \mathrm{mM}$ Tris-HCl buffer, $\mathrm{pH} 8.0$, was incubated to a required time of $0,1.25,2.5,5,10,15,20,25$, and 30 min, and then the supernatant was collected by centrifuging at $12000 \mathrm{~g}$ at $4^{\circ} \mathrm{C}$ for $10 \mathrm{~min}$. Concentration of the remaining enzyme was determined by Bradford's method, while concentration of the bound enzyme $\left(\mathrm{E}_{\mathrm{b}}\right)$ was calculated from the difference between the initial protein concentration $\left(\mathrm{E}_{\mathrm{t}}\right)$ and the free protein concentration $\left(\mathrm{E}_{\mathrm{f}}\right)$ after binding.

The chitin binding assay was also carried out with crystalline chitin and colloidal chitin (Sigma-Aldrich Pte Ltd., The Capricorn, Singapore Science Park II, Singapore) as tested polysaccharides. A reaction (set as above) was incubated for $60 \mathrm{~min}$ at $0^{\circ} \mathrm{C}$, then the chitin-bound enzyme was removed by centrifugation, and the concentration of the free enzyme was determined. For adsorption isotherm experiments, the reaction assay (also prepared as described above) containing varied concentrations of protein from 0 to $7.0 \mu \mathrm{M}$ was incubated for $60 \mathrm{~min}$. After centrifugation, concentration of free enzyme in the supernatant was determined. A plot of $\left[\mathrm{E}_{\mathrm{b}}\right]$ vs $\left[\mathrm{E}_{\mathrm{f}}\right]$ was subsequently constructed and the dissociation binding constants $\left(K_{\mathrm{d}}\right)$ of wild-type and mutants were estimated using 
a non-linear regression function in the GraphPad Prism software (GraphPad Software Inc., San Diego, CA).

\section{Steady-state kinetics}

Kinetic parameters of the chitinase variants were determined using chitohexaose or colloidal chitin as substrate. For chitohexaose, the reaction mixture $(200 \mu \mathrm{l})$, containing $0-500 \mu \mathrm{M}$ (GlcNAc) ${ }_{6}$, and $50 \mu \mathrm{g}$ enzyme in $100 \mathrm{mM}$ sodium acetate buffer, $\mathrm{pH} 5.5$, was incubated at $37^{\circ} \mathrm{C}$ for $10 \mathrm{~min}$. After boiling to $100^{\circ} \mathrm{C}$ for $3 \mathrm{~min}$, the entire reaction mixture was subjected to DMAB assay as described earlier. For colloidal chitin, the reaction was carried out the same way as the reducing-sugar assay, but concentrations of colloidal chitin were varied from 0 to $5.0 \%$ (w/v). The amounts of the reaction products produced from both substrates were determined from a standard curve of $[\mathrm{GlcNAc}]_{2}(0-1.75 \mu \mathrm{mol})$. The kinetic values were evaluated from three independent sets of data using the nonlinear regression function obtained from the GraphPad Prism software.

\section{Abbreviations}

GlcNAc $_{\mathrm{n}}$ : $\beta$-1-4 linked oligomers of $N$-acetylglucosamine residues where $\mathrm{n}=1-6$; DMAB: $p$-dimethylaminobenzaldehyde; IPTG: Isopropyl thio- $\beta$-D-galactoside; PMSF: Phenylmethylsulphonylfluoride.

\section{Authors' contributions}

SP performed site-directed mutagenesis, recombinant expression, protein purification, and functional characterization. CS carried out the sturcture-based sequence alignment and the molecular modeling of the tertiary structure of $\mathrm{V}$. carchariae chitinase A. WS initiated the ideas of research, was involved in primer design and site-directed mutagenesis, performed data analyses, and prepared the manuscript.

\section{Acknowledgements}

This work was financially supported by Suranaree University of Technology; The Thailand Research Fund (TRF) and The Thai Commission on Higher Education through a Research Career Development Grant to WS (grant no RMU4980028) and a TRF-Master Research Grant to SP (grant no MRG495S044).

\section{References}

I. Yu C, Lee AM, Bassler BL, Roseman S: Chitin utilization by marine bacteria. A physiological function for bacterial adhesion to immobilized carbohydrates. J Biol Chem 1991, 266:24260-24267.

2. Rast DM, Horsch M, Furter R, Gooday GW: A complex chitinolytic system in exponentially growing mycelium of Mucor rouxii: properties and function. J Gen Microbiol I99I, I 37:2797-2810.

3. Merzendorfer $\mathrm{H}$, Zimoch L: Chitin metabolism in insects:structure, function and regulation of chitin synthases and chitinases. J Exp Biol 2003, 206:4393-44I 2.

4. Herrera-Estrella A, Chet I: Chitinases in biological control. EXS 1999, 87: $17 \mid-184$

5. Melchers LS, Stuiver $\mathrm{MH}$ : Novel genes for disease-resistance breeding. Curr Opin Plant Biol 2000, 3: I47-I 52.
6. Patil RS, Ghormade VV, Deshpande MV: Chitinolytic enzymes: an exploration. Enzyme Microb Technol 2000, 26:473-483.

7. Donnelly LE, Barnes PJ: Acidic mammalian chitinase - a potential target for asthma therapy. TRENDS in Pharmacol Sci 2004, 25:509-5। I

8. Wills-Karp $M$, Karp $C L$ : Chitin checking-novel insights into asthma. N Engl J Med 2004, 35 I: |455-|457.

9. Terwisscha van Scheltinga AC, Kalk KH, Beintema JJ, Dijkstra BW: Crystal structures of hevamine, a plant defence protein with chitinase and lysozyme activity, and its complex with an inhibitor. Structure 1994, I 5: I 181-1 I89.

10. Perrakis A, Tews I, Dauter Z, Oppenheim AB, Chet I, Wilson KS, Vorgias CE: Crystal structure of a bacterial chitinase at $2.3 \AA$ resolution. Structure 1994, I5: I |69-I I80.

II. Hart PJ, Pfluger HD, Monzingo AF, Hollis T, Robertus JD: The refined crystal structure of an endochitinase from Hordeum vulgare L. seeds at $1.8 \AA$ resolution. J Mol Biol 1995, 248:402-4I3.

12. Watanabe T, Oyanagi W, Suzuki K, Tanaka H: Chitinase system of Bacillus circulans WL- 2 and importance of chitinase $A I$ in chitin degradation. J Bacteriol 1990, I 72:4017-4022.

13. Suzuki K, Sugawara N, Suzuki M, Uchiyama T, Katouno F, Nikaidou N, Watanabe T: Chitinases A, B, and CI of Serratia marcescens 2170 produced by recombinant Escherichia coli: enzymatic properties and synergism on chitin degradation. Biosci Biotechnol Biochem 2002, 66:1075-1083.

14. Montgomery MT, Kirchman DL: Role of chitin-binding proteins in the specific attachment of the marine bacterium Vibrio harveyi to chitin. Appl Environ Microbiol 1993, 59:373-379.

15. Tsujibo H, Orikoshi H, Baba N, Miyahara M, Miyamoto K, Yasuda M, Inamori $Y$ : Identification and characterization of the gene cluster involved in chitin degradation in a marine bacterium, Alteromonas sp. strain O-7. Appl Environ Microbiol 2002, 68:263-270.

16. Suginta $W$ : Identification of chitin binding proteins and characterization of two chitinase isoforms from Vibrio alginolyticus 283. Enzyme Microb Tech 2007, 4I:2I2-220.

17. Watanabe T, Ishibashi A, Ariga Y, Hashimoto M, Nikaidou N, Sugiyama J, Matsumoto T, Nonaka T: Trp I 22 and Trp I 34 on the surface of the catalytic domain are essential for crystalline chitin hydrolysis by Bacillus circulans chitinase AI. FEBS Lett 200I, 494:74-78.

18. Uchiyama T, Katouno F, Nikaidou N, Nonaka T, Sugiyama J, Watanabe $\mathrm{T}$ : Roles of the exposed aromatic residues in crystalline chitin hydrolysis by chitinase A from Serratia marcescens 2 I70. J Biol Chem 200I, 276:4I343-4I349.

19. Katouno F, Taguchi M, Sakurai K, Uchiyama T, Nikaidou N, Nonaka $\mathrm{T}$, Sugiyama J, Watanabe T: Importance of exposed aromatic residues in chitinase $B$ from Serratia marcescens 2170 for crystalline chitin hydrolysis. J Biochem (Tokyo) 2004, I 36: I 63-168.

20. Itoh Y, Watanabe J, Fukada H, Mizuno R, Kezuka Y, Nonaka T, Watanabe T: Importance of Trp59 and Trp60 in chitin-binding, hydrolytic, and antifungal activities of Streptomyces griseus chitinase C. Appl Microbiol Biotechnol 2006, 72: I I 76-I I 84.

21. Imai T, Watanabe T, Yui T, Sugiyama J: Directional degradation of beta-chitin by chitinase AI revealed by a novel reducing end labelling technique. FEBS Lett 2002, 5 I 0:20I-205.

22. Hult EL, Katouno F, Uchiyama T, Watanabe T, Sugiyama J: Molecular directionality in crystalline beta-chitin: hydrolysis by chitinases A and B from Serratia marcescens 2 I 70. Biochem J 2005, 388:85I-856.

23. Li Q, Wang F, Zhou Y, Xiao X: Putative exposed aromatic and hydroxyl residues on the surface of the $\mathbf{N}$-terminal domains of Chil from Aeromonas caviae CB I OI are essential for chitin binding and hydrolysis. Appl Environ Microbiol 2005, 7 I:7559-756 I.

24. Suginta W, Robertson PAW, Austin B, Fry SC, Fothergill-Gilmore LA: Chitinases from Vibrio: activity screening and purification of Chi A from Vibrio carchariae. J Appl Microbiol 2000, 89:76-84.

25. Suginta $W$, Vongsuwan A, Songsiriritthigul C, Prinz $H$, Estibeiro $P$ Duncan RR, Svasti J, Fothergill-Gilmore LA: An endochitinase A from Vibrio carchariae: cloning, expression, mass and sequence analyses, and chitin hydrolysis. Arch Biochem Biophys 2004, 424: 17|- 180.

26. Suginta W, Vongsuwan A, Songsiriritthigul C, Svasti J, Prinz H: Enzymatic properties of wild-type and active site mutants of chi- 
tinase A from Vibrio carchariae, as revealed by HPLC-MS. FEBS J 2005, 272:3376-386.

27. Tews I, Terwisscha van Scheltinga AC, Perrakis A, Wilson KS, Dijkstra BW: Substrate-assisted catalysis unifies two families of chitinolytic enzymes. J Am Chem Soc 1997, I 19:7954-7959.

28. Suginta W, Songsiriritthigul C, Kobdaj A, Opassiri R, Svasti J: Mutations of Trp275 and Trp397 altered the binding selectivity of Vibrio carchariae chitinase A. Biochim Biophys Acta 2007, 1770: II5I-II60.

29. Watanabe T, Ito Y, Yamada T, Hashimoto M, Sekine S, Tanaka H: The roles of the C-terminal domain and type III domains of chitinase AI from Bacillus circulans WL- 12 in chitin degradation. J Bacteriol 1994, 176:4465-4472.

30. Ikegami T, Okada T, Hashimoto M, Seino S, Watanabe T, Shirakawa M: Solution Structure of the chitin-binding domain of Bacillus circulans WL-I2 chitinase AI. J Biol Chem 2000, 275: |3654-|366|.

31. Li Y, Irwin DC, Wilson DB: Processivity, substrate binding, and mechanism of cellulose hydrolysis by Thermobifida fusca Cel9A. Appl Environ Microbiol 2007, 73:3165-3172.

32. Watanabe T, Ariga $Y$, Sato $U$, Toratani T, Hashimoto M, Nikaidou N, Kezuka $Y$, Nonaka T, Sugiyama J: Aromatic residues within the substrate-binding cleft of Bacillus circulans chitinase Al are essential for hydrolysis of crystalline chitin. Biochem J 2003, 376:237-244.

33. The National Resource for Biomedical Supercomputing (NRBSC) [http://www.psc.edu/biomed/genedoc/]

34. PredictProtein [http://www.predictprotein.org/]

35. Swiss-Model [http://swissmodel.expasy.org/]

36. Collaborative Computational Project, No.4: The CCP4 suite: programs for protein crystallography. Acta Crystallogr 1994, D50:760-763.

37. PyMol [http://www.pymol.org/]

38. Laemmli UK: Cleavage of structural proteins during the assembly of the head of bacteriophage T4. Nature 1970, 227:680-685.

39. Bradford MM: A rapid and sensitive method for the quantitation of microgram quantities of protein utilizing the principle of protein-dye binding. Anal Biochem 1976, 72:248-254

40. Hsu SC, Lockwood JL: Powdered chitin agar as a selective medium for enumeration of actinomycetes in water and soil. Appl Microbiol 1975, 29:422-426.

41. Bruce A, Srinivasan U, Staines HJ, Highley TL: Chitinase and laminarinase production in liquid culture by Trichoderma spp. and their role in biocontrol of wood decay fungi. Int Biodeterior Biodegrad 1995, 35:337-353.
Publish with Biomed Central and every scientist can read your work free of charge

"BioMed Central will be the most significant development for disseminating the results of biomedical research in our lifetime. "

Sir Paul Nurse, Cancer Research UK

Your research papers will be:

- available free of charge to the entire biomedical community

- peer reviewed and published immediately upon acceptance

- cited in PubMed and archived on PubMed Central

- yours - you keep the copyright 